\title{
Evaluating Psychological Skills of Japanese Amateur Baseball Referees
}

\author{
Masahiro Nishigai', Noriyuki Kida ${ }^{2 *}$ \\ ${ }^{1}$ Taisei Gakuin University High School, Osaka, Japan \\ ${ }^{2}$ Graduate School of Science and Technology, Kyoto Institute of Technology, Kyoto, Japan \\ Email: ${ }^{\star}$ kida@kit.ac.jp
}

How to cite this paper: Nishigai, M., \& Kida, N. (2018). Evaluating Psychological Skills of Japanese Amateur Baseball Referees. Advances in Physical Education, 8, 31-34. https://doi.org/10.4236/ape.2018.81004

Received: December 21, 2017

Accepted: February 8, 2018

Published: February 11, 2018

Copyright (c) 2018 by authors and Scientific Research Publishing Inc. This work is licensed under the Creative Commons Attribution International License (CC BY 4.0).

http://creativecommons.org/licenses/by/4.0/

\begin{abstract}
Psychological skills of amateur Japanese baseball referees were investigated based on whether or not they were qualified as a referee. A questionnaire to evaluate the psychological skills of referees was administered to referees $(\mathrm{N}=$ 218). Results indicated no differences in the psychological skills based on their qualifications. Also, examining the relationship between the age and years of experience and psychological skill indicated that "Self-control" and "Communication" skills were higher in older referees with longer experience $(p<.01)$. It is suggested that experience might be needed to improve psychological skills. On the other hand, there was no significant relationship between "Expressive power", "Confidence" and "Concentration".
\end{abstract}

\section{Keywords}

Baseball Referee, Psychological Characteristics

\section{Introduction}

Sports referees make judgements according to the rules of the game in different situations of the game. These judgements play a very important role in controlling the flow of the game and, as a matter of course, referees are considered to be right by players and team leaders. Moreover, referees feel that failures are unacceptable. Under such circumstances, quick judgments are required under strong stress and pressure (Anshel \& Weinberg, 1995; Mirjamali et al., 2012). Therefore, it is considered that high degree of psychological skills is required not only by athletes but also by referees in competitive sports. However, only a few studies have been conducted on referees. In addition, most of the researches on referees have been based on qualitative evaluations (Murakami et al., 2015). Therefore, this study was designed to quantitatively evaluate psychological characteristics of 
baseball referees and describe their characteristics.

In Japan, a system of qualifications for amateur baseball referees was inaugurated in April 2013 with the aim of improving the skills of amateur baseball referees and developing human resources. This study was designed to clarify the effects of being qualified as a referee on the psychological skill of a referee. It is also known that a referee's age and years of experience, among others, might also affect the psychological skills of a referee. Therefore, we examined the relationships between these factors.

\section{Method}

\subsection{Participants}

Amateur baseball referees $(\mathrm{N}=218)$ were surveyed in this study. Of the participants, $56.9 \%$ were qualified as baseball referees. Table 1 shows the age and years of experience as referees. It can be seen from the table that age and the years of experience were significantly higher for qualified referees (both, $p<.05$ ).

\subsection{Investigation}

We conducted a survey using a 24 item questionnaire developed to evaluate the psychological skills of referees. They responded using a 5-point scale consisting of "almost never", "rarely", "sometimes", "usually", and "always". The total score in responses to four questions on six factors was used to evaluate psychological skills: "Self-control", "Expressive power", "Motivation", "Confidence", "Communication", and "Concentration".

Survey was conducted by collective survey method. We distributed and collected questionnaires on occasion such as referee workshops.

\subsection{Analysis and Statistics Methods}

We examined the correlation between psychological skills scores and the age of the referee. If there was a significant correlation with age, an analysis of covariance was conducted with qualification (with, without) as inter-subject factors and age as a covariate. If there was not a significant correlation with age, an analysis of variance was conducted with qualification as inter-subject factors.

\section{Results}

Table 2 shows the correlation between psychological skills scores and the age of the referee. There were significant positive correlations between "Self-control"

Table 1. Participant's age and years of experience.

\begin{tabular}{ccccccc}
\hline & \multicolumn{2}{c}{ Non-Qualified } & \multicolumn{2}{c}{ Qualified } & & \\
\cline { 2 - 7 } & $M \pm S D$ & $95 \% C I$ & $M \pm S D$ & $95 \% C I$ & $F$ & $p$ \\
\hline Age & $41.5 \pm 11.0$ & {$[39.343 .8]$} & $44.8 \pm 10.8$ & {$[42.946 .7]$} & 4.83 & $.029^{*}$ \\
Experience & $12.5 \pm 7.5$ & {$[11.014 .0]$} & $15.2 \pm 8.2$ & {$[13.716 .7]$} & 6.21 & $.013^{*}$ \\
\hline
\end{tabular}

Note: ${ }^{\star} p<.05$. 
$(r=.273, p<.01)$ and "Communication" $(r=.215, p<.05)$ and not being qualified, whereas there were significant positive correlations between "Self-control" $(r=.416, p<.01)$, "Motivation" $(r=.226, p<.05)$, "Communication" $(r=.211$, $p<.05)$, and the total score $(r=.289, p<.01)$ with being qualified as a referee.

An analysis of covariance was conducted with qualification (with, without) as inter-subject factors and age as a covariate for "Self-control", "Motivation", "Communication" and the total score. Results of both variables indicated significance and parallelism of the regression, whereas no significant main effect was observed ("Self-control", $d=.194,(1-\beta)=.291$; "Motivation", $d=.095$, $(1-\beta)=.107$; “Communication", $d=.105,(1-\beta)=.120$; total score, $d=.114$, $(1-\beta)=.131)$. Moreover, an analysis of variance was conducted for "Expressive power", "Self-confidence", and "Concentration" with the qualification as the inter-subject factor. Results indicated no significant main effect for any of the variables("Expressive power", $d=.091,(1-\beta)=.101$; "Self-confidence", $d=.033$, $(1-\beta)=.057$; "Concentration", $d=.085,(1-\beta)=.095)$. Table 3 shows the average values for each group adjusted by age.

Table 2. Correlation between age and psychological characteristics.

\begin{tabular}{ccccccc}
\hline & \multicolumn{2}{c}{ Non-Qualified } & \multicolumn{2}{c}{ Qualified } & \multicolumn{2}{c}{ All } \\
\cline { 2 - 7 } & $r$ & $p$ & $r$ & $p$ & $r$ & $p$ \\
\hline Self-control & .273 & $.008^{* *}$ & .416 & $.000^{* *}$ & .360 & $.000^{* *}$ \\
Expressive power & .087 & .406 & .117 & .197 & .108 & .111 \\
Motivation & -.016 & .880 & .226 & $.012^{*}$ & .137 & $.044^{*}$ \\
Confidence & -.010 & .923 & .074 & .417 & .038 & .573 \\
Communication & .215 & $.037^{*}$ & .211 & $.019^{*}$ & .217 & $.001^{* *}$ \\
Concentration & -.044 & .675 & .154 & .087 & .065 & .336 \\
Total scores & .140 & .178 & .289 & $.001^{* *}$ & .232 & $.001^{* *}$ \\
\hline
\end{tabular}

Note: ${ }^{*} p<.05 ;{ }^{* *} p<.01$.

Table 3. Psychological characteristics.

\begin{tabular}{ccccccc}
\hline & \multicolumn{2}{c}{ Non-Qualified } & \multicolumn{2}{c}{ Qualified } & & \\
\cline { 2 - 7 } & $M \pm S D$ & $95 \% C I$ & $M \pm S D$ & $95 \% C I$ & $F$ & $p$ \\
\hline Self-control & $13.0 \pm 3.2$ & {$[12.313 .6]$} & $13.6 \pm 3.0$ & {$[13.014 .1]$} & 1.91 & .168 \\
Expressive power & $14.0 \pm 3.4$ & {$[13.414 .7]$} & $14.3 \pm 3.2$ & {$[13.814 .9]$} & .39 & .533 \\
Motivation & $17.5 \pm 1.9$ & {$[17.117 .9]$} & $17.7 \pm 2.3$ & {$[17.318 .1]$} & .73 & .395 \\
Confidence & $12.4 \pm 3.0$ & {$[11.813 .0]$} & $12.5 \pm 3.0$ & {$[11.913 .0]$} & .04 & .852 \\
Communication & $16.8 \pm 1.8$ & {$[16.417 .2]$} & $17.0 \pm 2.0$ & {$[16.717 .4]$} & .61 & .436 \\
Concentration & $15.2 \pm 2.2$ & {$[14.815 .7]$} & $15.0 \pm 2.5$ & {$[14.515 .4]$} & .58 & .445 \\
Total scores & $88.9 \pm 10.1$ & {$[86.991 .0]$} & $90.1 \pm 11.0$ & {$[88.192 .0]$} & .63 & .429 \\
\hline
\end{tabular}




\section{Discussion}

Results of this study indicated no differences in the psychological skills resulting from referees having or not having qualifications. In Japan, the system of qualification for referees was developed only recently, which possibly accounted for this result. In other words, people without a qualification as a referee could nevertheless be good judges, suggesting that being qualified as a referee might not reflect the diverse skills demanded of a referee.

The relationship between the psychological skills score and age indicated that older referees had more "Self-control" and "Communication". Therefore, it is suggested that experience is needed to improve the psychological skills of referees. On the other hand, there was no significant relationship between "Expressive power", "Confidence" and "Concentration". This could be because of the influence of factors other than those which simply improve with accumulating experience (Guillen \& Feltz, 2011). Therefore, it is suggested that effective training programs for improving the psychological skills of referees should focus on their "Expressive power", "Motivation", "Self-confidence" and "Concentration".

\section{References}

Anshel, M., \& Weinberg, R. (1995) Sources of Acute Stress in American and Australian Basketball Referees. Journal of Applied Sport Psychology, 7, 11-22. https://doi.org/10.1080/10413209508406297

Guillen, F., \& Feltz, D. (2011) A Conceptual Model of Referee Efficacy. Frontiers in Psychology, 2, 1-5. https://doi.org/10.3389/fpsyg.2011.00025

Mirjamali, E., Ramzaninezhad. R., Rahmaninia, F., \& Reihani, M. (2012) A Study of Sources of Stress in International and National Referees of Soccer, Volleyball, Basketball and Handball in Iran. World Journal of Sport Sciences, 6, 347-354.

Murakami, K., Hirata, D., \& Sato, S. (2015) Psychological Characteristics of Top Referees: Based on Results of Interviews with Referees. Research Journal of Sports Performance, 8, 76-87. (In Japanese) 